\title{
Formação continuada em Neuroeducação: percepção de professores sobre a neurociência e sua importância para a educação
}

\author{
Geórgia Elisa Filipin \\ georgiaefilipin@gmail.com \\ Franciele Casarotto \\ francasarotto@hotmail.com \\ Pâmela Billig Mello-Carpes \\ panmello@hotmail.com \\ Universidade Federal do Pampa | Brasil \\ Liane da Silva de Vargas \\ lianeevargas@gmail.com \\ Universidade Federal do Rio Grande do Sul| Brasil
}

\section{Resumo}

A neurociência contribui para a compressão de como o cérebro aprende, qualificando a escolha de estratégias de ensino e aprendizagem. Aqui, objetivamos relatar a percepção e o conhecimento de professores acerca da neurociência antes e após um curso de formação continuada. 0 curso foi realizado em duas etapas, contando com adesão de 13 docentes. Segundo os mesmos, a neurociência não havia sido abordada na formação inicial de 69,2\% deles; $77,7 \%$ relatou ter algum conhecimento acerca do tema adquirido por outros meios que não a educação formal. Ao final, todos conceituaram neurociência adequadamente, afirmando que esta tem uma importante relação com a educação.

\section{Palavras-chave}

Formação de Professores, Neurociência, Cérebro. 


\section{Introdução}

Não entender por completo um processo é como possuir uma visão míope, distorcida e duvidosa do mesmo. Neste sentido, pode-se dizer que a neurociência é como uma lente que busca estudar e investigar as funções do Sistema Nervoso Central (SNC) de diversas formas (SILVA; MORINO; 2012). Como uma vertente interdisciplinar da neurociência, a neuroeducação é uma área recente que busca aplicar os conhecimentos da neurociência para auxiliar na compreensão dos processos biológicos da aprendizagem, colaborando, assim, para elaboração de novas estratégias pedagógicas de ensino (BLAKEMORE; FRITH, 2000).

Promover situações de aprendizagem nas quais todos possam estimular e desenvolver seu potencial é indispensável quando se busca oportunizar o melhor desempenho individual dos discentes. 0 diálogo dos conhecimentos neurocientíficos com a prática dentro das salas de aula se torna, desta forma, indispensável (CARVALHO, 2010). No campo da educação, o conhecimento sobre o desenvolvimento do cérebro potencializa a compressão do educador, possibilitando-o conhecer melhor o aluno enquanto sujeito da aprendizagem (CUERVO, 2008).

Como membro ativo e principal da construção do conhecimento, o professor necessita estar capacitado para compreender e atender as diferenças cognitivas de seus alunos de acordo com os princípios da neurociência, contribuindo com a melhora das práticas educativas (ESCRIBANO, 2007). Ao atualizar seus conhecimentos, os docentes permitem-se ter uma nova visão metodológica e prática, impulsionando o ensino e atendendo às dificuldades específicas de seus discentes, conseguindo, assim, facilitar a aprendizagem, bem como minimizar as dificuldades de aprendizagem.

Diante do exposto, o objetivo deste artigo é relatar a percepção e o conhecimento de professores da Educação Básica acerca da neurociência e suas contribuições para a educação antes e após um curso de formação continuada em Neurociência Aplicada à Educação. ${ }^{1}$

\footnotetext{
10 artigo traz resultados de um subprojeto parte do programa POPNEURO: Ações para divulgação e popularização da neurociência, realizado em Uruguaiana-RS, com apoio do edital PROEXT/MEC, Programa Novos Talentos/CAPES, e Unipampa.
} 


\section{Metodologia}

O curso ocorreu entre os meses de novembro e dezembro de 2015 e foi organizado em duas etapas: (a) Conhecimentos acerca da neurociência e a educação; e, (b) Aplicação prática dos conhecimentos, e contou com a participação de professores da rede pública de Educação Básica do município de Uruguaiana/RS, totalizando 30h de atividades. Inicialmente, foi realizada a divulgação do curso nas escolas públicas, Coordenadoria Regional de Educação e Secretaria Municipal de Educação, seguida pela aberturado período para inscrição, que deveria ser realizada por e-mail. Foram ofertadas trinta vagas, aos primeiros trinta inscritos.

Os professores participantes foram submetidos a uma avaliação inicial para verificar quais eram os seus conhecimentos prévios acerca da Neurociência (Tabela 1). Tais informações foram úteis não somente para avaliação da efetividade das ações, mas também para o seu planejamento.

Tabela 1: Questionário inicial, aplicado no primeiro encontro do Curso de Neurociência aplicada à Educação.

\begin{tabular}{|c|c|}
\hline Sexo: & Idade: \\
\hline \multicolumn{2}{|l|}{ Formação inicial (graduação): } \\
\hline \multicolumn{2}{|c|}{ Pós-graduação: ( ) Sim. Qual?______ ) Não } \\
\hline \multicolumn{2}{|c|}{$\begin{array}{l}\text { Leciona em qual etapa? ( ) Pré-escola ( ) Ensino Fundamental - séries iniciais ( ) Ensino Fundamental } \\
\text { - séries finais ( ) Ensino Médio }\end{array}$} \\
\hline \multicolumn{2}{|c|}{ Leciona em escola: ( ) Estadual ( ) Municipal ( ) Particular } \\
\hline \multicolumn{2}{|c|}{$\begin{array}{l}\text { Durante a sua formação inicial, você teve alguma disciplina que abordasse neurociência? } \\
\text { ( ) Sim ( ) Não. Se sim, que aspectos você lembra terem sido abordados? }\end{array}$} \\
\hline \multicolumn{2}{|l|}{ O que você entende por Neurociência? } \\
\hline \multicolumn{2}{|c|}{ Você já teve contato com a Neurociência antes? ( ) Sim ( ) Não. Se sim, onde e como foi? } \\
\hline \multicolumn{2}{|l|}{ Quais são as suas perspectivas acerca deste curso? } \\
\hline a & 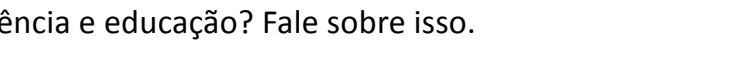 \\
\hline
\end{tabular}

Fonte: Material elaborado pelos autores.

Ao final das atividades, os participantes foram solicitados a responder outro questionário, apresentado na tabela 2 . 
Tabela 2: Questionário final, aplicado após os encontros teórico-práticos do Curso de Neurociência aplicada à Educação.

O que você entende por Neurociência?

Em sua opinião, existe alguma relação entre neurociência e educação? Fale sobre isso.

Você já fazia uso de atividades práticas, tais como atividades envolvendo uso de tecnologias da informação e experimentação, em sala de aula?

Você acredita que os exemplos práticos usados durante o curso são de ( ) fácil /( ) difícil execução em sala de aula.

Qual dos temas abordados durante o curso foi uma novidade para você?

( ) Experimentação. ( ) TICs e jogos. ( ) Hands-on. ( ) Nenhum.

Você acredita que esse curso vai colaborar com a sua prática docente? Se sim, como?

$\mathrm{O}$ curso realizado atendeu as suas expectativas? Comente.

Considerando uma escala de 0 a 10 (sendo 10 a maior nota e 0 a menor), atribua uma nota ao curso realizado:

Se você tiver observações, sugestões ou comentários adicionais a nossa equipe, por favor, forneça-os neste espaço. Agradecemos sua valiosa participação!

Fonte: Material elaborado pelos autores.

\subsection{0 curso}

O curso foi organizado em duas etapas principais. A Etapa I: Neurociência Aplicada à Educação teve como objetivo discutir conhecimentos da Neurociência e sua contribuição para a prática escolar, proporcionando um espaço para a discussão entre os participantes, viabilizando a troca de conhecimentos e experiências vivenciadas. 0 curso foi ministrado por integrantes do "Programa de extensão Popneuro: ações para popularização e divulgação da neurociência", alunos dos cursos de graduação em Enfermagem, Farmácia e Fisioterapia da Universidade Federal do Pampa, do Programa de Pós-graduação em Bioquímica, e pela professora coordenada. Todos os ministrantes foram previamente treinados e o material para o curso foi preparado e avaliado pela equipe.

Nesta etapa, oito temas foram trabalhos de forma teórico-aplicada. Em cada tema foi realizada uma explanação teórica, seguida por um exemplo de aplicabilidade prática e, por fim, por uma discussão em grupo (figura 1). Ao longo das discussões as ideias norteadoras apresentadas pelos participantes foram registradas. 


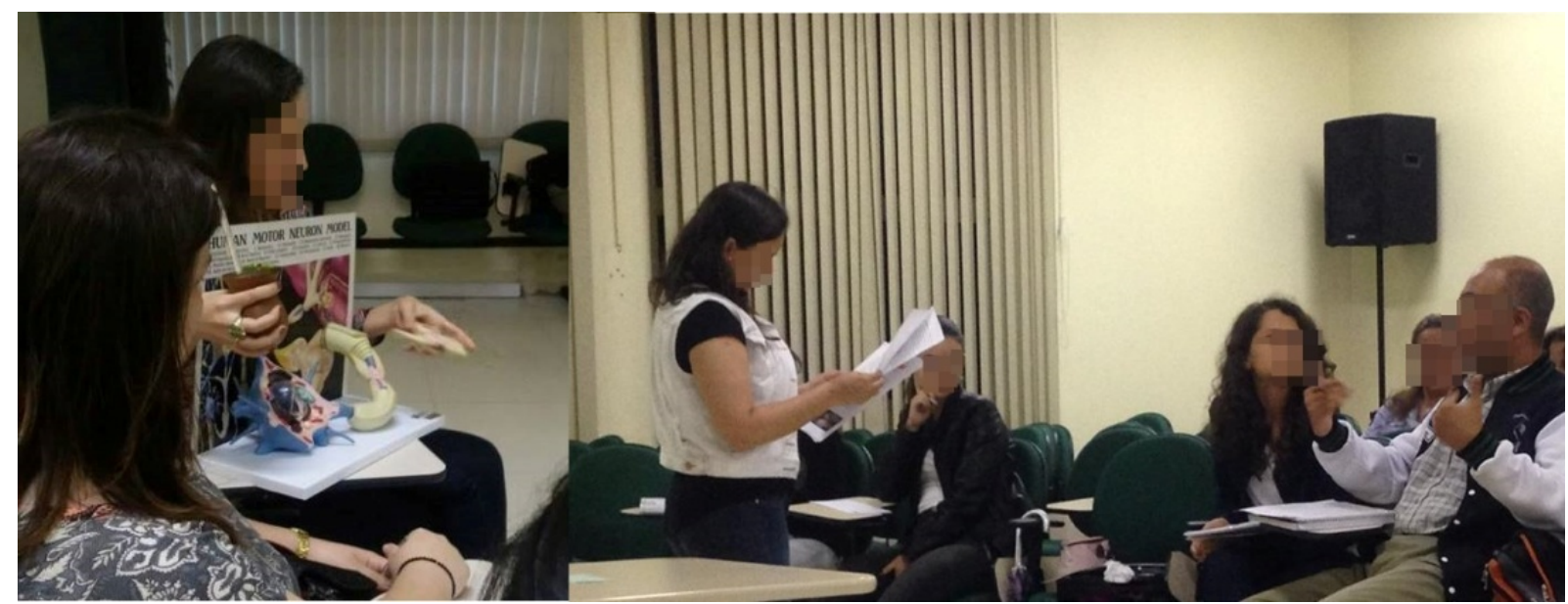

Figura 1: Curso de Neurociência aplicada à Educação: momentos de discussão entre os participantes. Fonte: Material produzido pelos autores.

Os principais temas trabalhados foram:

a) Organização do SN: Foram abordados aspectos relacionados à organização geral do SN, incluindo suas divisões, seus componentes e suas funções. Foram utilizadas peças anatômicas sintéticas para melhor compreensão das características do SN.

b) Desenvolvimento do SN e Neuroplasticidade: Conceitos como desenvolvimento do $\mathrm{SN}$, neuroplasticidadee aspectos relacionados ao ambiente e sua influência na aprendizagem foram trabalhados. Após discussão, foi proposto que os professores lessem notícias relacionadas ao tema, discutindo as informações e identificando-as como verídicas ou não, com base em conhecimentos prévios.

c) Memória e a importância da atenção e da emoção para o aprendizado: Foram apresentados conceitos relacionados ao processo de formação da memória e fatores que podem interferir nele. Após, cada professor recebeu uma folha com três labirintos iguais, e foram orientados a achar a saída de cada labirinto, observando o tempo levado para o término de cada um, de forma que pudessem perceber que, à medida que repetiam a atividade e passavam a conhecer o labirinto conseguiam finalizá-lo de forma mais rápida. Os professores também puderam vivenciar a importância da atenção para o aprendizado através da realização de um teste de tempo de reação em duas condições distintas: atenção total ao teste e atenção dividida (entre o teste e o telefone celular). 
d) Funções Executivas: Para abordagem desse tema foi proposto uma explanação sobre as funções executivas e sua importância para o desenvolvimento dos alunos durante a vida escolar e adulta, sendo, ao final, trabalhada uma situaçãoproblema.

e) Processos neurobiológicos da leitura: Foram discutidos os processos neurobiológicos envolvidos na leitura, bem como as áreas do cérebro responsáveis, a importância da atenção para esta função e também distúrbios neurológicos relacionados à leitura, tais como a dislexia.

f) $O$ cérebro e os números: Nesta temática foram considerados conceitos relacionados à matemática, linguagem, discriminação de quantidades e habilidade de realizar cálculos simples, senso numérico e regiões cerebrais envolvidas nesses processos. Ainda foram trabalhados e discutidos conceitos como a dislexia e discalculia e a diferença entre estas condições. Ao final, os professores foram apresentados a um caso real de discalculia. Após a leitura do caso puderam discutir a respeito e sugerir estratégias de ensino que contribuíssem com este caso.

g) Inteligência e dificuldades de aprendizagem: Nesta etapa conversamos sobre inteligência e dificuldades de aprendizagem e também alguns transtornos que envolvem alterações de estruturas cerebrais, como a síndrome de Down, transtorno de espectro autista, síndrome de Asperger, transtorno de déficit de atenção/hiperatividade (TDAH). Situações reais trazidas pelos professores a partir de suas experiências prévias contribuíram para as discussões neste tema.

h) Diálogo entre Neurociência e Educação: Para finalizar esta primeira etapa foi discutida a relação existente entre a neurociência e a educação e como se dá (ou deveria se dar) a comunicação entre as duas.

A Etapa II: Aplicação prática dos conhecimentos teve como objetivo propor atividades práticas que os professores poderiam aplicar em sala de aula considerando a neurobiologia cerebral. Inicialmente foram retomados alguns conceitos sobre a neurociência, a importância da interação entre a universidade e a escola, da contribuição da popularização da ciência no contexto escolar e comunitário. As atividades práticas desse curso foram divididas em três oficinas, descritas a seguir, nas quais os professores 
Formação continuada em Neuroeducação

participaram em pequenos grupos, para melhor aproveitamento. Em cada oficina um grupo de tutores fazia o papel de mediador, orientando a condução das atividades. Todos os professores tiveram oportunidade de realizar todas as oficinas.

\section{Oficina 1: Experimentação:}

Em um laboratório da Universidade o grupo de professores foi organizado em três subgrupos, ficando cada grupo em uma bancada. Um conjunto de materiais e uma temática a ser trabalhada foram disponibilizados a cada grupo, de forma que eles deveriam pensar em como utilizar os materiais para uma prática de experimentação relacionada àquela temática, criando perguntas que pudessem ser respondidas através dos experimentos. Tal metodologia considera a participação ativa do aluno, estimula sua curiosidade e criatividade, facilitando o aprendizado ao envolver emoção e atenção às tarefas.

Alguns exemplos dos experimentos realizados pelos docentes estão representados na figura 2: modelo de sistema respiratório com uso de balões, garrafa PET e mangueira, com o objetivo entender o funcionamento do sistema respiratório; criação de uma "bebida colorida" com o objetivo brincar com diferentes densidades de líquidos; "fusão de cores", experimento que objetivou brincar com a tensão superficial da água. Além disso, outros conceitos e práticas relacionados a temáticas como osmose, contração muscular, misturas e outros temas também foram propostos.

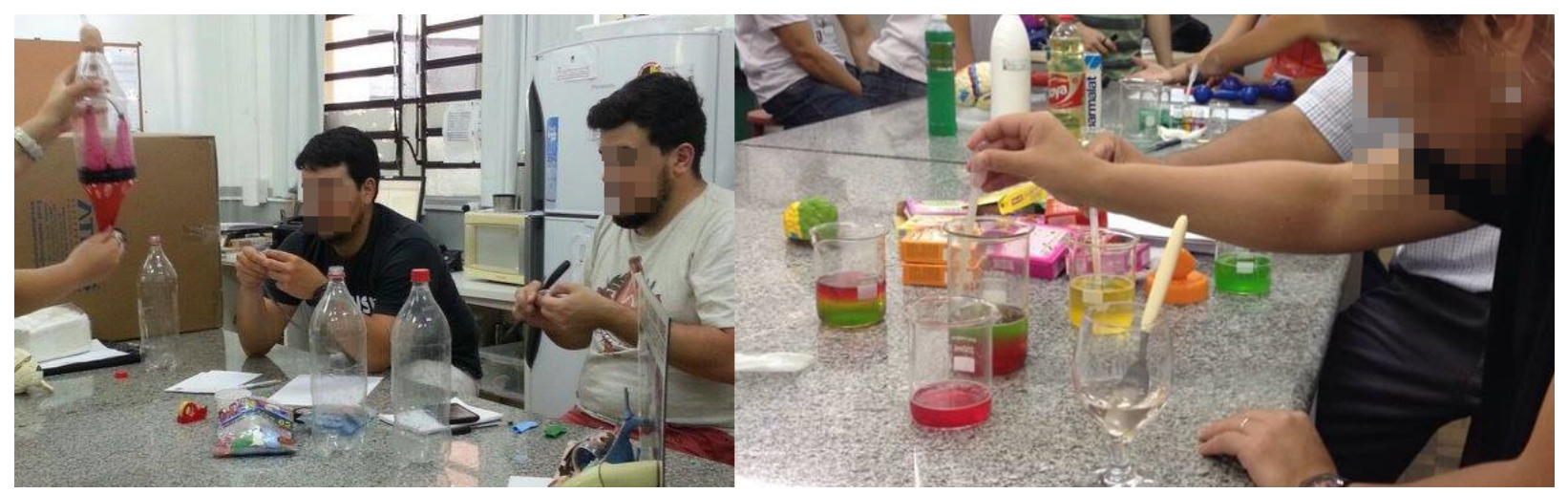

Figura 2: Professores participantes do Curso de Neurociência aplicada à Educação em oficina de experimentação.

Fonte: Material produzido pelos autores. 
Formação continuada em Neuroeducação

Oficina 2: Tecnologias de Informação e Comunicação (TICs) e jogos:

Os professores foram organizados em subgrupos para trabalhar temáticas que desafiaram o uso de TICs, como celulares/smartphones, tablets, computadores, etc. no ensino (figura 3). Foi discutido como estas tecnologias podem colaborar com o processo ensino-aprendizagem e experimentado o uso destes equipamentos como ferramenta de pesquisa e fonte de informação. Também foi demonstrada a aplicabilidade de jogos do tipo "Lego" e dominó, além de alguns jogos adaptados pelos professores para trabalhar conceitos específicos.

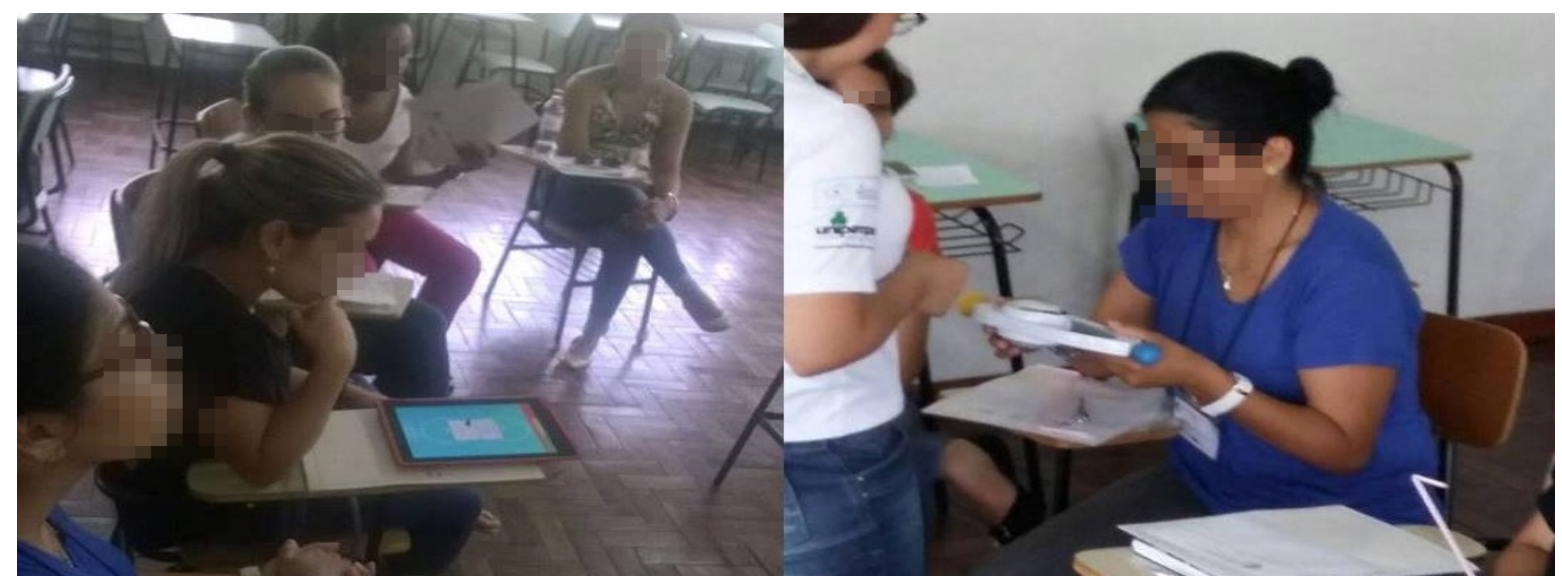

Figura 3: Professores participantes do Curso de Neurociência aplicada à Educação durante a oficina de Tecnologias de Informação e Comunicação (TICs).

Fonte: Material produzido pelos autores.

\section{Oficina 3: "Hands-on"}

Nessa atividade os professores receberam materiais como cartolina, cola, canetas, tampas, entre outros, e foram desafiados a desenvolver uma atividade prática que pudesse ser aplicadas em sala de aula no ensino de algum conteúdo didático. Durante a oficina os professores desenvolveram modelos anatômicos de células com E.V.A, neurônios com garrafas PET, capacetes em forma de cérebro com uso de bolas de isopor, entre outros. Ao término das atividades práticas, foi aberto um espaço para discussões a respeito das atividades realizadas. 


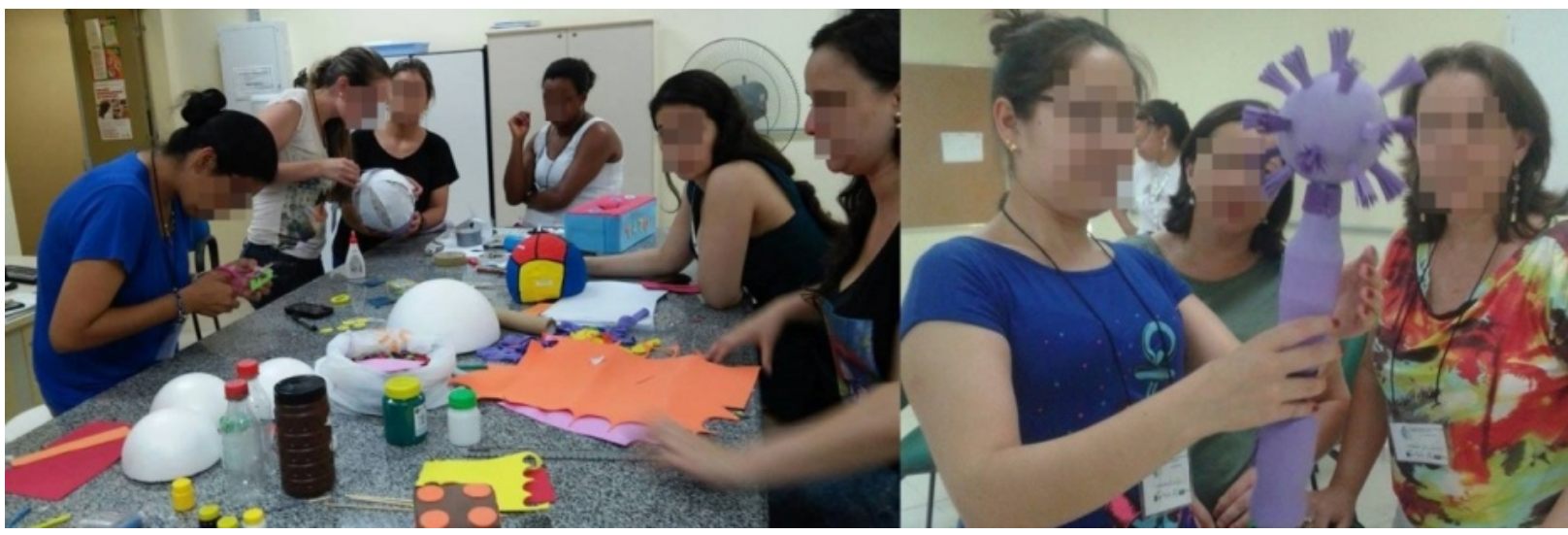

Figura 4: Professores participantes do Curso de Neurociência aplicada à Educação durante a oficina "Hands-on". Fonte: Material produzido pelos autores.

\subsection{Análise dos resultados}

Os resultados quantitativos foram analisados utilizando estatística descritiva, sendo apresentados em sua frequência relativa (\%). Os resultados qualitativos foram analisados através da técnica de análise de conteúdo, envolvendo três etapas: (1) préanálise, (2) exploração do material, e, (3) tratamento dos resultados obtidos e interpretação (MINAYO, 1992).

\subsection{Aspectos éticos}

Todos os procedimentos propostos neste trabalho foram aprovados pelo Comitê de Ética da Universidade Federal do Pampa (parecer número 1.791.981).

\section{Resultados e Discussão}

Dentre os 30 professores inscritos, 13 participaram de todas as etapas do curso (12 do sexo feminino e 1 do masculino, idade média de $37 \pm 17$ anos), os demais justificaram a ausência. A tabela 3 descreve as características dos professores, em termos de formação e atuação docente. 
Formação continuada em Neuroeducação

Tabela 3: Características dos professores participantes do Curso de Neurociência aplicada à Educação

\begin{tabular}{|l|l|l|l|}
\hline 1. & \multicolumn{2}{|c|}{ 3. Etapa em que lecionam os professores } \\
\hline $61,5 \%$ & Pedagogia & $23,5 \%$ & Pré-escola \\
\hline $7,7 \%$ & Matemática & $23,5 \%$ & Ensino Fundamental - séries iniciais \\
\hline $7,7 \%$ & Letras & $11,8 \%$ & Ensino Fundamental - séries finais \\
\hline $7,7 \%$ & Educação Física & $17,6 \%$ & Coordenação/Direção \\
\hline $7,7 \%$ & Fisioterapia & $23,6 \%$ & Não lecionava \\
\hline $7,7 \%$ & Ciências da Natureza & \multicolumn{2}{|l|}{} \\
\hline 2. & Gós-graduação dos professores & 4. Tipos de escolas em que lecionam os professores \\
\hline 1 Professor & Gestão Escolar & $70 \%$ & Escolas Municipais \\
\hline 3 Professores & Educação Infantil & $30 \%$ & Escolas Estaduais \\
\hline 2 Professores & Pscicopedagogia & \multicolumn{2}{|l}{} \\
\hline
\end{tabular}

Fonte. Material produzido pelos autores.

Apenas 30,8\% dos professores relatou ter cursado disciplinas relacionadas com a neurociência na sua formação inicial; nestas foram abordados aspectos como o funcionamento do SN e as dificuldades de aprendizagem. De acordo com Soares (2003), os conteúdos relacionados à neurociência ainda são timidamente expostos durante a formação de pedagogos, uma vez que dentre os 352 cursos de Pedagogia pesquisados pelo autor, apenas 6,25\% contemplavam as disciplinas de neurociência e/ou correlatas. Ainda, dentre todas as instituições brasileiras pesquisadas que ofertam Programa Especial de Formação Pedagógica para Docentes, nenhuma contemplou disciplinas relacionadas à neurociência (SOARES, 2003).

Apesar da notável ausência da neurociência na formação inicial dos professores, pôde-se perceber que eles possuíam algum conhecimento acerca de temas básicos da neurociência (figura 5). 


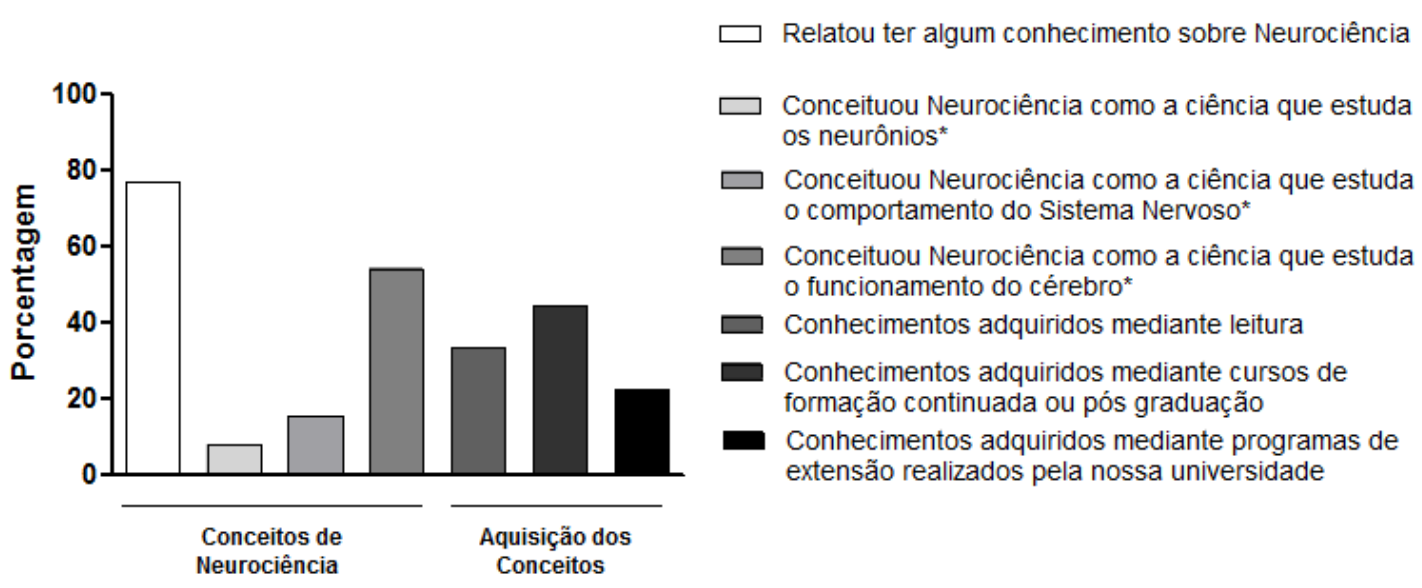

Figura 5: Conhecimento dos professores acerca de temas básicos da neurociência e formas de aquisição. ( $\left.{ }^{*}\right)$ Referente aos participantes que relataram ter algum conhecimento sobre Neurociência.

Fonte: Material produzido pelos autores.

Quando questionados sobre suas perspectivas acerca do curso e o que lhes levou a se inscrever, os professores responderam que tinham muitas perspectivas, sendo as principais: entender o funcionamento do SN aplicado à prática docente e compreender as dificuldades de aprendizagem. Esses achados corroboram com os encontrados por Goswami (2006) que relatou sua experiência ao divulgar a neurociência no âmbito escolar:

\footnotetext{
"Primeiramente é imensa a boa vontade que os professores e educadores têm para com a neurociência - eles estão muito interessados em neurociência, eles sentem que nós temos o potencial de fazer descobertas importantes sobre a aprendizagem humana e estão ansiosos para aprender sobre estas descobertas e contribuir com ideias e sugestões."
}

Assim, podemos perceber que os professores reconhecem a importância dos conhecimentos neurocientíficos para a qualificação do processo ensino-aprendizagem e estão dispostos a entendê-los e aplicá-los de forma coerente em sala de aula. Isso é de uma importância ímpar para o desenvolvimento da educação no Brasil. Há poucos anos uma pesquisa que avaliou os sistemas educacionais de 39 países e uma região (Hong Kong e China) e identificou que nosso país se encontra em penúltimo lugar em termos de resultados de leitura, ciências e matemática na Educação Básica, indicando que a alfabetização desses alunos não é plenamente efetiva (PEARSON, 2012). Ainda, em nosso país, o número de analfabetos atinge cerca de 12,9 milhões, segundo o relatório de 2012 da Pesquisa Nacional por Amostra de Domicílios (Pnad). 
Os motivos para tal cenário de déficit na efetiva alfabetização dos nossos alunos podem ser variados, mas o fracasso escolar também está relacionado à desmotivação do aluno perante o processo ensino-aprendizagem. Já se sabe o quanto a motivação no ambiente escolar é um fator determinante para a qualidade de aprendizagem e desempenho escolar (PAIVA E LOURENÇO, 2010) e, sem dúvida, os conhecimentos de neurociência possibilitam que o professor conheça melhor o funcionamento do cérebro de seus alunos e, assim, opte por estratégias didáticas que podem conferir maior motivação ao aprendizado.

Grossi (2014) nos traz ainda, que outra possibilidade para que se possa diminuir esse fracasso escolar é aceitar as diversidades presentes em sala de aula. Assim, torna-se de fundamental importância que os professores estejam capacitados para compreender as individualidades nos processo de compreensão, entendimento e aprendizado de seus alunos, para que dessa forma, possam maximizar seus potenciais e minimizar suas dificuldades, facilitando e efetivando esse processo. E, para isso, para que se tenha esse entendimento por parte dos professores, é necessário que os mesmos tenham conhecimento de como o cérebro funciona, suas dificuldades e como aprender colabora na prática educacional, colaborando assim, com a diminuição das dificuldades de aprendizado (ESCRIBIANO, 2007). Neste sentido, ao final do curso percebemos que houve um aumento do entendimento dos professores a respeito do tema abordado, conforme pode ser verificado na figura 6.

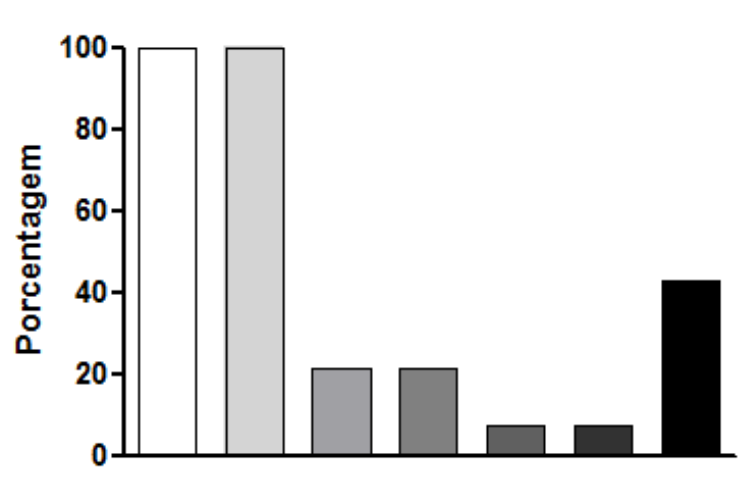

$\square$ Conceituou coerentemente o que é
Neurociência
Afirmaram existir uma relação entre a
Neurociência e a Educação
Desenvolvimento cognitivo X entendimento
dos processos educativos*
$\square$ Neurociência X comprovação das teorias de
educação*
Inteligências múltiplas X dificuldade de
aprendizagem
Funcionamento cerebral X estratégias
educacionais ${ }^{\star}$
Promove o aprimoramento das práticas
pedagógicas ${ }^{\star}$

Figura 6: Conhecimento dos professores acerca de temas básicos da neurociência e sua relação com a educação ao final do curso. $\left({ }^{*}\right)$ Referente à justificativa da relação existente entre a neurociência e a educação. Fonte: Material produzido pelos autores. 
Estes dados se concretizam nas ideias percebidas nas falas dos docentes ao longo do curso, como podemos ver na figura7.

\begin{tabular}{|c|c|}
\hline $\begin{array}{l}\text { "a neurociência como possibilidade de } \\
\text { compreender a base neurobiológica } \\
\text { das teorias de alguns pedagogos, } \\
\text { como Paulo Freire" }\end{array}$ & $\begin{array}{l}\text { "a impossibilidade de ver a educação } \\
\text { separada da neurociência" } \\
\text { "a educação também pode trazer } \\
\text { algo para a neurociência" }\end{array}$ \\
\hline $\begin{array}{l}\text { "o fortalecimento dos laços entre a } \\
\text { neurociência e a educação" }\end{array}$ & $\begin{array}{l}\text { "a legitimidade da neurociência } \\
\text { para a educação" }\end{array}$ \\
\hline $\begin{array}{l}\text { "os múltiplos fatores que podem } \\
\text { interferir no ensino-aprendizagem e na } \\
\text { biologia cerebral, incluindo contexto } \\
\text { social, alimentação, sono, etc." }\end{array}$ & $\begin{array}{l}\text { "a crítica à educação } \\
\text { tradicional/bancária, que não } \\
\text { considera conceitos de neurociência" }\end{array}$ \\
\hline
\end{tabular}

Figura 7: Falas dos professores participantes ao longo curso, na quais se pode perceber o entendimento dos laços e relação entre a neurociência e a educação.

Fonte: Material produzido pelos autores.

Ao longo do curso percebeu-se o grande envolvimento dos professores nas atividades práticas e discussões propostas, como se pôde perceber durante a execução de uma atividade proposta na etapa I, temática dificuldade de aprendizagens. Nesta atividade os professores foram organizados em pequenos grupos e cada um recebeu um caso de um aluno com dificuldades de aprendizagem, em cada caso a dificuldade era diferente. Cada grupo deveria ler e discutir o caso, e, ao final propor estratégias de ensino que, considerando os conhecimentos de neurociência, poderiam auxiliar este aluno. Verificou-se que, embora os "problemas" que causavam as dificuldades dos alunos fossem variados e diferentes, as estratégias foram muito semelhantes, e, em todos os grupos, incluíram: estimular o envolvimento da turma com o aluno, potencializar suas qualidades e preferências, propor desafios adequados ao aluno (e, para isso, é preciso conhecer a situação - importância da neurociência), respeitar o tempo do aluno (sua individualidade) e motivar/elogiar.

Sobre a segunda etapa do curso, os professores afirmaram que as atividades de experimentação, o uso de TICs e jogos e as atividades do tipo "hands-on" podem ser de fácil aplicação em sala de aula e são importantes contribuintes para a efetiva aprendizagem escolar. Podemos verificar que muitos professores já aplicavam de 
Formação continuada em Neuroeducação

maneira similar este tipo de atividade em sala de aula, entretanto alguns desses temas e metodologias eram desconhecidos, ao menos em relação aos termos utilizados (figura 8).

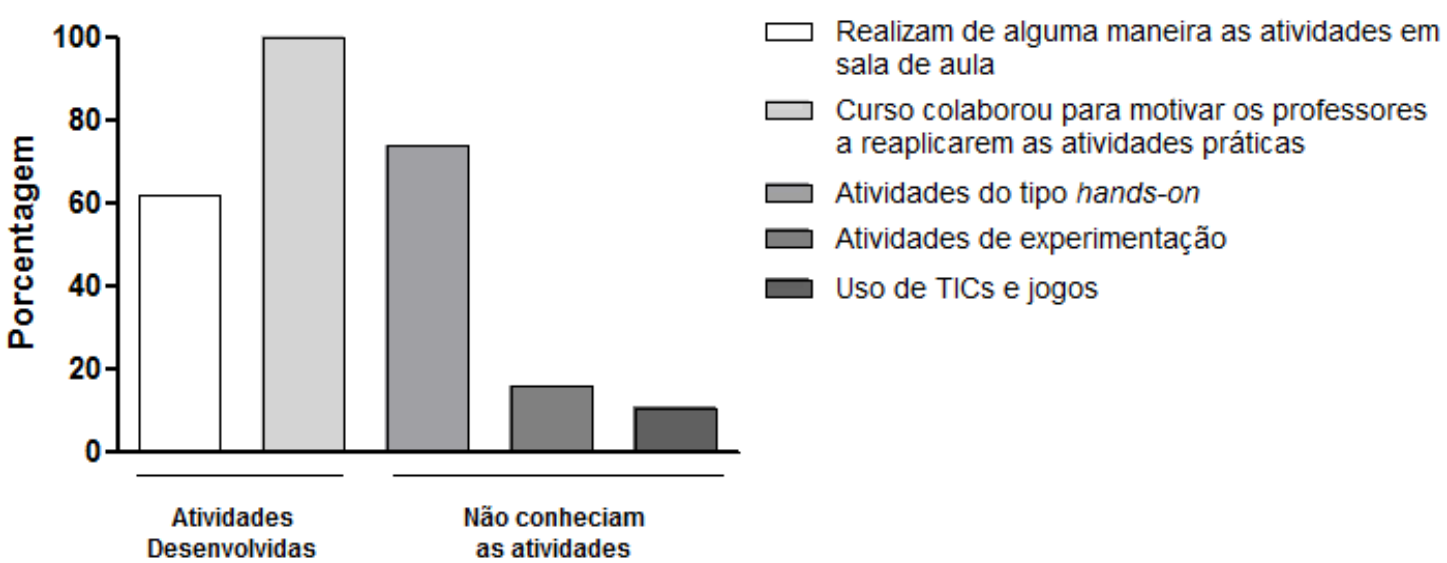

Figura 8: Atividades práticas utilizadas pelos professores em sala de aula e tipos de atividades que eles declararam não conhecer previamente ao curso.

Fonte: Material produzido pelos autores.

Benite (2009) afirma que a experimentação desperta o interesse dos alunos devido ao seu caráter lúdico e motivador, essencialmente vinculado aos sentidos. Já os ambientes virtuais e as ferramentas de comunicação atuam através de uma maior interatividade, colaboração e cooperação entre os envolvidos, fazendo com que os mesmos tenham o desejo de aprender, construir e superar limites através de uma condição coletiva (AGUIAR, 2008). Considerando que as atividades práticas, que envolvem "mão na massa" (cientificamente mais conhecidas pelo termo em inglês "hands on"), favorecem o pensar, as atitudes, aproximando a educação e a ciência (ANDRADE, MASSABNI, 2011), é importante que ações de formação embasadas na neurociência promovam a qualificação docente para inserção de práticas no ambiente escolar.

Ao questionarmos os professores sobre a importância dos mesmos terem conhecimentos sobre a neurociência, foi consenso que a neurociência pode auxiliar e ampliar a prática educacional, uma vez que proporciona um maior entendimento do processo ensino-aprendizagem. Além disso, ela é importante nas intervenções e planejamento de aulas, e auxilia no entendimento do aluno como ser social individual, com necessidades próprias e diferentes maneiras de aprender. Ainda, os professores 
destacaram que o curso fortaleceu os laços entre a neurociência e a educação, e reconheceu a escola como espaço de aplicação dos conceitos de neuroeducação, neuroplasticidade, etc., já que todas as atividades e discussões propostas foram situações contextualizadas ao dia-a-dia da sala de aula, de forma que o curso gerará um impacto positivo nas suas aulas e planejamentos, que passarão a ser mais reflexivos e contextualizados.

Desta forma, foi unanimidade dentre os professores afirmar que o curso superou suas expectativas iniciais, trazendo reflexões importantes para a prática pedagógica. Além disso, eles destacaram como pontos positivos do curso as apresentações claras e de fácil comunicação, e os bons diálogos/discussões gerados, fatores que levaram à popularização do saber científico de uma forma efetiva e de fácil aplicabilidade. Quando solicitados a atribuir uma nota de 0 a 10 para o curso, a nota média atribuída foi de 9,9.

\section{Considerações Finais}

Pode-se perceber que ainda é tímido o conhecimento dos professores acerca de temas relacionados com a neurociência e sua importância para a educação, e que cursos de formação continuada nesta temática podem ser estratégias interessantes e viáveis para a divulgação e promoção de conhecimentos neurocientíficos aplicados à educação. Tal estratégia pode preencher esta lacuna da formação inicial dos professores promovendo a melhora do entendimento do funcionamento do cérebro e do processo ensino-aprendizagem, qualificando a escolha de metodologias de ensino, e, por consequência, melhorando a qualidade da educação em nosso país ao favorecer o interesse e a motivação dos alunos em aprender.

\section{REFERÊNCIAS}

AGUIAR, E. V. B.. As novas tecnologias e o ensino aprendizagem. Revista Vértices, v. 10, n. $1 / 3, \quad$ p. 63-71, 2008. Disponível em: http://essentiaeditora.iff.edu.br/index.php/vertices/article/view/1809-

2667.20080006. Acesso em: 15 nov. 2016.

ANDRADE, M.L F.; MASSABNI, V.G.O desenvolvimento de atividades práticas na escola: um desafio para os professores de ciências. Revista Ciência e Educação, v. 17, n. 4, p. 835-854, 2011. 
http://www.scielo.br/scielo.php?script=sci_arttext\&pid=S151673132011000400005\&lng=pt\&nrm=iso\&tlng=en. Acesso em: 15 nov. 2016.

BENITE A. M. C.; BENITE C. R. M. O laboratório didático no ensino de química: uma experiência no ensino público brasileiro. Revista Iberoamericana de Educación, v. 2, n. 48, p. 1-10, 2009. Disponível em: <http://rieoei.org/2770.htm>. Acesso em: 15 nov. 2016.

BLAKEMORE, S. J.; FRITH, U.The impliclations of recent developments in neuroscience for research on teaching and learning.Journal of The Institute of Training \& Occupational Learning, v. 2, n. 2, p. 23-42, 2000. Disponível em: http://www.edumed.org.br/papers/EAD/referencias/types-of-learning.pdf. Acesso em: 15 nov. 2016.

CARVALHO, F. A. H. Neurociências e educação: uma articulação necessária na formação docente. Trabalho Educação e Saúde, v. 8, n. 3, p. 537-550, 2010/2011. Disponível em: http://www.scielo.br/scielo.php?pid=S1981-

77462010000300012\&script=sci_abstract\&tlng=es. Acesso em: 15 nov. 2016.

CUERVO L. Música para um cérebro em transformação: Reflexões sobre a música na adolescência. In: SIMPÓSIO DE COGNIÇÃO E ARTES MUSICAIS, 2008, São Paulo. Anais SIMCAM IV. USP, 2008.

ESCRIBANO, C. L. Contribuciones de la neurociencia al diagnóstico y tratamiento educativo de la dislexia deldesarrollo. Revista de Neurología, v. 44, n. 3, p. 173-180, 2007. Disponível em: http://www.neurologia.com/pdf/Web/4403/x030173.pdf. Acesso em: 15 nov. 2016.

GOSWAMI, U. Neuroscience and education: from research to practice? Naturereviewsneuroscience, v. 7, n. 5, p. 406-413, 2006. Disponível em http://www.nature.com/nrn/journal/v7/n5/full/nrn1907.html. Acesso em: 15 nov. 2016.

GROSSI, M. G. R; LOPES, A.M.; COUTO, P. A. Aneurociência na formação de professores: um estudo da realidade brasileira; Revista da FAEEBA - Educação e Contemporaneidade, v. 23, n. 41, p. 27-40, 2014 Disponível em: http://www.revistas.uneb.br/index.php/faeeba/article/view/821. Acesso em: 15 nov. 2016.

LOURENÇO A.A; PAIVA M.O. A motivação escolar e o processo de aprendizagem. Revista Ciências \& Cognição, v. 15, n. 2, p. 132-141. 2010. Disponível em: http://www.cienciasecognicao.org/pdf/v15_2/12_132-141_m313.pdf. Acesso em: 15 nov. 2016.

MINAYO, M. C. S. O desafio do conhecimento: pesquisa qualitativa em saúde. Revista Saúde e Sociedade, v. 1, n. 2, p. 141, 1992. Disponível em: 
http://www.scielo.br/scielo.php?script=sci_arttext\&pid=S0104-12901992000200009. Acesso em: 15 nov. 2016.

PEARSON. The learning curve. Disponível em: http://thelearningcurve.pearson.com>. Acesso em: 15 nov. 2016.

IBGE. Pesquisa Nacional por Amostra de Domicílios. Disponível em: http://www.ibge.gov.br/home/estatistica/populacao/trabalhoerendimento/pnad2012/ default_sintese.shtm. Acesso em: 15 nov. 2016.

SILVA,F. MORINO, C.R.A importância das neurociências na formação de professores, Revista Momento - Diálogos em Educação, v. 21, n. 1, p. 29-50, 2012. Disponível em: http://www.seer.furg.br/momento/article/view/2478. Acesso em: 15 nov. 2016.

SOARES, D. (Org.). Os vínculos como passaporte da aprendizagem: um encontro D’EUS. Rio de Janeiro: Caravansarai. 2003.

WOLFE,P. Brain Research and Education: Fad or Foundation? Loex conference proceedings 2007, v. 38, p. 3-6. 2011 Disponível em: http://commons.emich.edu/loexconf2007/38. Acesso em: 15 nov. 2016 
Continuing Education in Neuroeducation: teacher' perception about neuroscience and its importance for education

\begin{abstract}
Neuroscience contribute to the compression about how the brain learn, qualifying the choice of teaching-learning strategies. Here, we aim to report the perception and knowledge of school teachers about neuroscience before and after a training course. The course was made in two stages, counting with 13 teachers. $69.2 \%$ of the teachers did not have contact with neuroscience during their initial training. $77.7 \%$ claimed to have some knowledge acquired by other means. Still, all participants conceptualized neuroscience properly and said that this science has an important relationship with education.
\end{abstract}

Key-words: Teachers' Training, Neuroscience, Brain.

Original submetido em: 15 nov. 2016

Aceito para publicação em: 1ำ jul. 2017

\section{Fomación Continua en Neuroeducación: la percepción de los maestros acerca de la neurociencia y su importancia para la educación}

Resumen: La neurociencia contribuye con la compresión de como el cerebro aprende, cualificando la elección de estrategias para enseñanza y aprendizaje. Aquí nuestro objetivo es informar de la percepción y el conocimiento de los maestros sobre la neurociencia antes y después de un curso de educación continua. El curso se realizó en dos etapas, con la adhesión de 13 maestros. Segundo los maestros, la neurociencia no estaba cubierta en la formación básica de 69,2\% de éstos; 77,7\% tiene algún conocimiento adquirido por otros medios. Al final, la neurociencia fue conceptualizada adecuadamente por todos, que indicaran que ella tiene una relación importante con la educación.

Palavras clave: Formación del profesorado, Neurociencia, Cerebro.

Sobre os autores:

\section{Geórgia Elisa Filipin}

Bacharel em Fisioterapia pela Universidade Federal do Pampa, Brasil

\section{Franciele Casarotto}

Acadêmica do curso de Fisioterapia, Universidade Federal do Pampa, Brasil

\section{Liane da Silva de Vargas}

Doutoranda do Programa de Pós-graduação em Ciências Biológicas: Fisiologia da Universidade Federal do Rio Grande do Sul (UFRGS) e professora colaboradora no curso de Especialização em Neurociência Aplicada à Educação da Universidade Federal do Pampa, Brasil.

\section{Pâmela Billig Mello-Carpes}

Fisioterapeuta. Mestre e doutora em CB: Fisiologia (UFRGS). Pósdoutorado na área de neurofisiologia (KUL, Bélgica). Atua na Universidade Federal do Pampa - Campus Uruguaiana, Brasil. 